University of Nebraska - Lincoln

DigitalCommons@University of Nebraska - Lincoln

9-9-2002

\title{
Oxidation of metals at the chromium oxide interface
}

\author{
Ruihua Cheng \\ University of Nebraska-Lincoln
}

C.N. Borca

University of Nebraska-Lincoln

N. Pilet

University of Nebraska-Lincoln

Bo Xu

University of Nebraska-Lincoln

Lu Yuan

University of Nebraska-Lincoln, lyuan2@bigred.unl.edu

See next page for additional authors

Follow this and additional works at: https://digitalcommons.unl.edu/physicsdowben

Part of the Physics Commons

Cheng, Ruihua; Borca, C.N.; Pilet, N.; Xu, Bo; Yuan, Lu; Doudin, Bernard; Liou, Sy_Hwang; and Dowben, Peter A., "Oxidation of metals at the chromium oxide interface" (2002). Peter Dowben Publications. 17. https://digitalcommons.unl.edu/physicsdowben/17

This Article is brought to you for free and open access by the Research Papers in Physics and Astronomy at DigitalCommons@University of Nebraska - Lincoln. It has been accepted for inclusion in Peter Dowben Publications by an authorized administrator of DigitalCommons@University of Nebraska - Lincoln. 


\section{Authors}

Ruihua Cheng, C.N. Borca, N. Pilet, Bo Xu, Lu Yuan, Bernard Doudin, Sy_Hwang Liou, and Peter A. Dowben 


\title{
Oxidation of metals at the chromium oxide interface
}

\author{
Ruihua Cheng, C. N. Borca, ${ }^{a)}$ N. Pilet, ${ }^{\text {b) }}$ Bo Xu, L. Yuan, B. Doudin, S. H. Liou, \\ and P. A. Dowben ${ }^{\mathrm{c}}$ \\ Department of Physics and Astronomy and the Center for Materials Research and Analysis, \\ Behlen Laboratory of Physics, University of Nebraska-Lincoln, Lincoln, Nebraska 68588-0111
}

(Received 12 June 2002; accepted for publication 23 July 2002)

\begin{abstract}
Metal thin-film deposition, over the $\mathrm{Cr}_{2} \mathrm{O}_{3}$ surface of $\mathrm{CrO}_{2}$ thin-film substrates, exhibits a redox reaction at the interface. The transition metal forms an oxide in combination with the reduction of the near-surface chromium oxide to $\mathrm{Cr}_{2} \mathrm{O}_{3}$. The insulating barrier layer $\mathrm{Cr}_{2} \mathrm{O}_{3}$ increases with the formation of $\mathrm{Pb}_{3} \mathrm{O}_{4}$ in $\mathrm{Pb} / \mathrm{Cr}_{2} \mathrm{O}_{3} / \mathrm{CrO}_{2}$ and $\mathrm{CoO}$ in $\mathrm{Co} / \mathrm{Cr}_{2} \mathrm{O}_{3} / \mathrm{CrO}_{2}$ junctions, respectively. (C) 2002 American Institute of Physics. [DOI: 10.1063/1.1506942]
\end{abstract}

Electric transport in ferromagnetic-insulatingferromagnetic (FM-I-FM) systems has attracted a lot of attention since 1995. ${ }^{1,2}$ If the insulating layer is thin enough (less than $2 \mathrm{~nm}$ ), the electron tunneling probability becomes significant. Changes of the resistance, typically $20 \%$ as a function of the applied field, have been observed in magnetic junctions, though values as high as $400 \%$ are known. Existing junction magnetoresistance data are mostly restricted to $\mathrm{Al}_{2} \mathrm{O}_{3}$ oxide as the insulating barrier layer, though a number of other oxide barrier layers, ${ }^{3}$ including $\mathrm{Cr}_{2} \mathrm{O}_{3}{ }^{4,5}$ have been recently explored.

Chromium oxides have been seriously considered as spin-polarized electron injectors to spin-tunnel junctions. ${ }^{4-7}$ Nonetheless, Co oxidation at $\mathrm{NiO}$-oxide interfaces is now fairly well established. ${ }^{8-10}$ This raises significant questions about the composition of insulating oxide barrier layers and the coupling of the ferromagnet at the barrier interface. Oxide magnetic/insulator superlattices consisting of $\mathrm{Fe}_{3} \mathrm{O}_{4} / \mathrm{NiO},{ }^{11-13}$ and $\mathrm{NiO} / \mathrm{CoO}^{14-16}$ have been fabricated but superexchanges appear to be suppressed in the insulating systems and the interlayer coupling is confined primarily to the interface region and therefore sensitive to interface morphology. ${ }^{8-10}$ Because of the interest in both superconductor-insulating-ferromagnetic ${ }^{4}$ and FM-I$\mathrm{FM}^{1-3}$ junctions, we have examined the reduction and oxidation reaction that accompanies the deposition of both a superconductor $(\mathrm{Pb})$ and a transition metal ferromagnet $(\mathrm{Co})$ on the stable $\mathrm{Cr}_{2} \mathrm{O}_{3}$ insulating surface of $\mathrm{CrO}_{2}$.

$\mathrm{Cr}_{2} \mathrm{O}_{3} / \mathrm{CrO}_{2}$ samples were made by two techniques. In one approach, samples were made of a thin Cr film (30 nm thick) sputtered on a clean $\mathrm{Si}$ wafer and oxidized in partial oxygen pressure. We reproduced the synthesis route of Rowell and Shen, ${ }^{17}$ with the samples heated $14 \mathrm{~h}$ at $470 \mathrm{~K}$ in 730 mbar oxygen partial pressure. The observed current-voltage curve of the resulting film was strongly reminiscent of the so-called "giant resistance peak" observed by Rowell and Shen on Cr-I-Ag tunnel junctions. ${ }^{17}$ The insulator "I" in

\footnotetext{
a) Present address: JILA, University of Colorado, Boulder, CO 80305-3328.

b) Also at: Department of Physics, Ecole Polytechnique Fédérale de Lausanne, CH-1015 Lausanne, Switzerland.

${ }^{c)}$ Author to whom all correspondence should be addressed at: Department of Physics and Astronomy, 255 Behlen Laboratory of Physics, University of Nebraska, Lincoln, NE 68588-0111; electronic mail: pdowben@unl.edu
}

their junctions was also fabricated by oxidation of a $\mathrm{Cr}$ film, and the anomaly attributed to the presence of magnetic $\mathrm{CrO}_{2}$ and $\mathrm{Cr}_{2} \mathrm{O}_{3}$. Angle-resolved x-ray photoemission (ARXPS) investigations of these films, ${ }^{18}$ allowed us to differentiate between $\mathrm{CrO}_{2}$ and $\mathrm{Cr}_{2} \mathrm{O}_{3}$. We find a mixture of these two oxides, being phase separated after longer annealing times, and becoming a superposition of $\mathrm{CrO}_{2}$ and $\mathrm{Cr}_{2} \mathrm{O}_{3}$ thin films after even longer annealing. The observed resistance per unit area down values of $500 \mathrm{k} \Omega / \mu \mathrm{m}^{2}$ was surprisingly low for such thick barriers. ${ }^{19}$ Our measurements indicate that this thickness is more likely corresponding to a conducting thin (4-5 nm) $\mathrm{CrO}_{2}$ film covered by a thinner (1-2 nm) $\mathrm{Cr}_{2} \mathrm{O}_{3}$ insulating barrier. ${ }^{20}$ In our other approach to $\mathrm{CrO}_{2}$ thin-film fabrication, the $\mathrm{CrO}_{2}$ thin films were fabricated by epitaxial growth though chemical vapor deposition, with $\mathrm{CrO}_{3}$ as the molecular precursor, on single-crystal rutile $\mathrm{TiO}_{2}(100)$ substrates. Increasing temperature leads to decomposition of $\mathrm{CrO}_{3}$ but at $390{ }^{\circ} \mathrm{C}$, the reaction leads to growth of a stable $\mathrm{CrO}_{2}$ phase. The x-ray diffraction data exhibits the sharp diffraction lines characteristic of high quality epitaxial $\mathrm{CrO}_{2}$ thin films grown on $\mathrm{TiO}_{2}$ (100).

Prior to ARXPS studies, samples were cleaned by sputtering and annealing to remove surface contamination. $5,18,20$ From the outset, i.e., from the initial stages of surface preparation, the core-level binding energies indicated that the stable surfaces were $\mathrm{Cr}_{2} \mathrm{O}_{3}$. X-ray photoemission (XPS) measurements were obtained using the $\mathrm{Mg} K \alpha$ line radiation $(1253.6 \mathrm{eV})$. Both the $\mathrm{Cr} 2 p$ and $\mathrm{O} 1 s$ core levels were investigated as a function of emission angle for the various thin film samples, along with the $\mathrm{Pb} 4 f$ and $\mathrm{Co} 2 p$ core levels following metal deposition. The emission angle is defined with respect to the surface normal, and binding energies are reported with respect to the Fermi level of the metal (Au, Co, $\mathrm{Ta}$, and $\mathrm{Pb}$ ) in intimate contact with the sample and compared with binding energies similarly assigned. Photoemission final state effects, similar to surface photovoltage effects, have been extensively characterized and eliminated. ${ }^{5}$ Valence-band spectra were obtained using $\mathrm{He}$ II $(h \nu$ $=40.8 \mathrm{eV}$ ), at room temperature as well, and the photoelectrons were collected normal to the surface.

The ARXPS Cr $2 p$ data for different $\mathrm{Cr}_{2} \mathrm{O}_{3} / \mathrm{CrO}_{2}$ samples, both following the preparation of the clean stable $\mathrm{Cr}_{2} \mathrm{O}_{3}$ surface oxide, and following the deposition of $\mathrm{Pb}$ and 


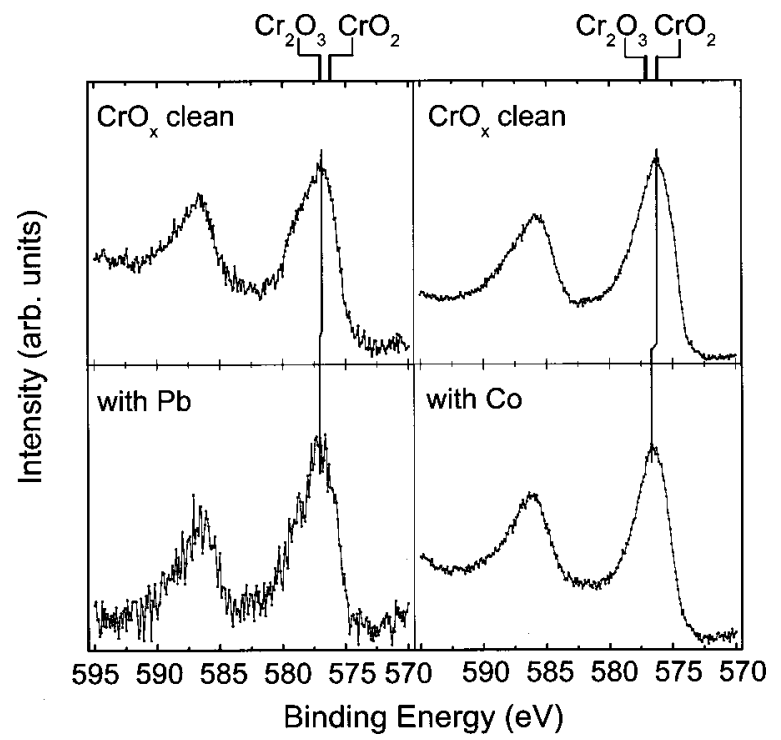

FIG. 1. Room-temperature $\mathrm{Cr} 2 p$ core-level XPS taken on a different sample surface at normal emission angle. The literature values of $\mathrm{Cr} 2 p_{3 / 2}$ binding energy for both $\mathrm{Cr}_{2} \mathrm{O}_{3}$ and $\mathrm{CrO}_{2}$ are marked on the top. Left-hand side upper panel is the XPS data for clean $\mathrm{CrO}_{x}$ surface and the left-hand side lower panel is the XPS data for the $\mathrm{CrO}_{x}$ sample with $\mathrm{Pb}$ evaporated. Right-hand side upper panel also shows the data for clean $\mathrm{CrO}_{x}$ surface and the right-hand side lower panel shows the data for the $\mathrm{CrO}_{x}$ with Co evaporated on the top.

$\mathrm{Co}$, are plotted in Fig. 1. Pb was evaporated on top of samples fabricated by the approach of Rowell and Shen, ${ }^{17}$ while the $\mathrm{Co}$ was evaporated on the epitaxial $\mathrm{Cr}_{2} \mathrm{O}_{3} / \mathrm{CrO}_{2}$ samples on single-crystal $\mathrm{TiO}_{2}$. As expected, $\mathrm{Cr} 2 p$ corelevel spectra show that the clean surface is dominated by the stable $\mathrm{Cr}_{2} \mathrm{O}_{3}$ surface oxide. The binding energy of the major $\mathrm{Cr} 2 p_{3 / 2}$ core-level contribution in most of our thin-film samples is about $576.8 \pm 0.2 \mathrm{eV}$ which generally corresponds to the accepted binding energy for $\mathrm{Cr}_{2} \mathrm{O}_{3}$ oxide. ${ }^{21}$ The other $\mathrm{Cr} 2 p_{3 / 2}$ core-level peak contributions are generally somewhat lower (but very strong in the $\mathrm{CrO}_{2}$ grown on $\mathrm{TiO}_{2}$ ), at about $576.3 \pm 0.3 \mathrm{eV}$, and this suggests the $\mathrm{CrO}_{2}$ oxide. ${ }^{22}$ The presence of both $\mathrm{CrO}_{2}$ and $\mathrm{Cr}_{2} \mathrm{O}_{3}$ oxide phases in the surface region is more apparent in the oxygen core-level spectra.

With transition metal deposition on the $\mathrm{Cr}_{2} \mathrm{O}_{3} / \mathrm{CrO}_{2}$ samples, there are two obvious changes $\mathrm{Cr} 2 p_{3 / 2}$ (and $\operatorname{Cr} 2 p_{1 / 2}$ ): first, the shift of the $\operatorname{Cr} 2 p_{3 / 2}$ peak to higher binding energies with thin $\mathrm{Pb}$ or $\mathrm{Co}$ deposition, and second, the full width at half maximum (FWHM) decreases with $\mathrm{Pb}$ or Co deposition (Fig. 1). This is very apparent for Co deposited on top of the $\mathrm{Cr}_{2} \mathrm{O}_{3} / \mathrm{CrO}_{2}$ thin film. Before Co growth, the binding energy of $\mathrm{Cr} 2 p_{3 / 2}$ is $576.3 \pm 0.2 \mathrm{eV}$ but with a large FWHM, indicative of a thin layer of $\mathrm{Cr}_{2} \mathrm{O}_{3}$ residing ontop of $\mathrm{CrO}_{2} \cdot{ }^{18}$ After deposition of the equivalent of 3 monolayers (ML) of $\mathrm{Co}$, the $\mathrm{Cr} 2 p_{3 / 2}$ binding energy increases to $576.7 \pm 0.2 \mathrm{eV}$ with smaller a FWHM. This binding energy is more representative of the $\mathrm{Cr}_{2} \mathrm{O}_{3}$ phase and the smaller FWHM indicates a decreased amount of the $\mathrm{CrO}_{2}$ phase superimposed in the spectra. This indicates that either some $\mathrm{CrO}_{2}$ has been reduced to the native $\mathrm{Cr}_{2} \mathrm{O}_{3}$ increasing the amount of $\mathrm{Cr}_{2} \mathrm{O}_{3}$ or, because of the limited mean-free path, the deposition of $\mathrm{Co}$ or $\mathrm{Pb}$ diminished the sampling of the $\mathrm{CrO}_{2}$ that lies below the native $\mathrm{Cr}_{2} \mathrm{O}_{3}$ oxide at the metal/ Downloaded 05 Sep 2006 to 129.93.16.206. Redistribution subject

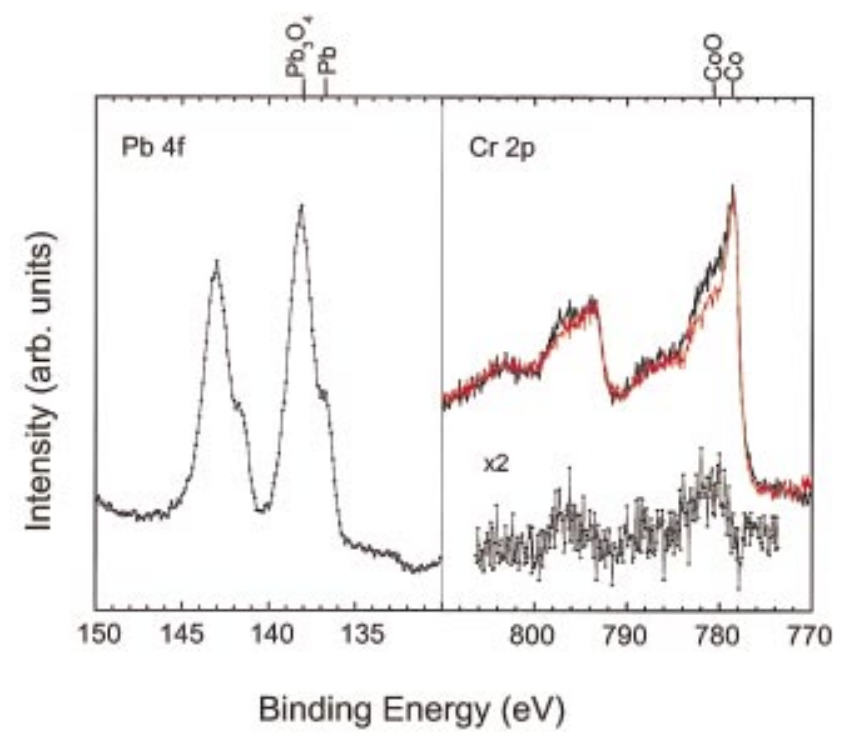

FIG. 2. (Color) Left-hand side panel shows the core-level XPS of $\mathrm{Pb} 4 f$ taken at room temperature with normal emission angle. Right-hand side panel shows the ARXPS of Co $2 p$ at room temperature. The black curve is the spectrum taken at normal emission angle while the red curve is the spectrum taken at $60^{\circ}$ emission angle and the difference of these two spectra is plotted in the bottom.

oxide interface. A combination of both effects is also possible.

Both $\mathrm{Pd}$ and $\mathrm{Co}$ oxidize at the $\mathrm{Cr}_{2} \mathrm{O}_{3}$ interface, upon deposition. As seen in the left-hand side panel of Fig. 2, core-level photoemission of both $\mathrm{Pb} 4 f_{7 / 2}$ and $4 f_{5 / 2}$ show sharp peaks combined with a significant shoulder instead of the simple expected $4 f$ doublet. The binding energy for the main core-level feature $\mathrm{Pb} 4 f_{7 / 2}$ is $131.1 \pm 0.2 \mathrm{eV}$ corresponds to the accepted binding energy for $\mathrm{Pb}_{3} \mathrm{O}_{4}{ }^{23}$ and the binding energy of the accompanying shoulder is 136.7 $\pm 0.2 \mathrm{eV}$, which is the core-level binding energy expected for metallic $\mathrm{Pb}^{24}$

Evidence of $\mathrm{CoO}$ formation at the $\mathrm{Co} / \mathrm{Cr}_{2} \mathrm{O}_{3}$ interface, for $\mathrm{CrO}_{2}$ epitaxial samples, is found after the deposition of 3 monolayer Co. The Co $2 p_{3 / 2}$ XPS spectra, for both normal emission angle (black) and $60^{\circ}$ emission (red), plotted in Fig. 2, exhibit two strong overlapping features. The binding energy of $\mathrm{Co} 2 p_{3 / 2}$ major peak, at $776.8 \pm 0.2 \mathrm{eV}$, corresponds to the metallic Co binding energy. ${ }^{25}$ The $2 p_{3 / 2}$ corelevel feature at $780.2 \pm 0.2 \mathrm{eV}$ is generally associated with the binding energy of $\mathrm{CoO} .{ }^{26}$ The relative intensities of these two features depends upon the emission angle, and as the emission angle increases and photoemission becomes more surface sensitive, the high binding energy Co $2 p_{3 / 2}$ core level decreases relative to the other Co $2 p$ core-level features. Since the Co $2 p_{3 / 2}$ core-level feature at $780.2 \pm 0.2 \mathrm{eV}$ is suppressed at the larger emission angles, it is clear that $\mathrm{CoO}$ resides below the metallic $\mathrm{Co}$, or rather, Co oxidizes at the interface between $\mathrm{Co}$ and $\mathrm{Cr}_{2} \mathrm{O}_{3} / \mathrm{CrO}_{2}$.

From Fig. 1, we conclude that $\mathrm{Pb}$ undergoes oxidation to $\mathrm{Pb}_{3} \mathrm{O}_{4}$ at the $\mathrm{Pb} / \mathrm{Cr}_{2} \mathrm{O}_{3}$ interface while $\mathrm{Co}$ is oxidized into $\mathrm{CoO}$ at the interface between $\mathrm{Co}$ and $\mathrm{Cr}_{2} \mathrm{O}_{3} / \mathrm{CrO}_{2}$. For both $\mathrm{Pb} / \mathrm{Cr}_{2} \mathrm{O}_{3} / \mathrm{CrO}_{2}$ and $\mathrm{Co} / \mathrm{Cr}_{2} \mathrm{O}_{3} / \mathrm{CrO}_{2}$ junctions, chemical mass balance requires that the oxidation of the $\mathrm{Pb}$ or Co must be accompanied by either reduction of $\mathrm{CrO}_{2}$ to $\mathrm{Cr}_{2} \mathrm{O}_{3}$, with an associated increase in the $\mathrm{Cr}_{2} \mathrm{O}_{3}$ layer thickness and oxyto AIP license or copyright, see http://apl.aip.org/apl/copyright.jsp 


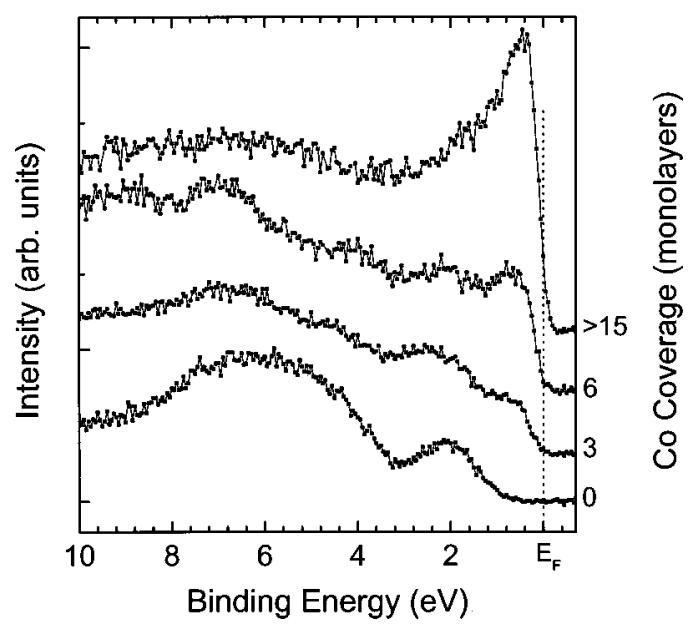

FIG. 3. Valence-band photoemission spectra taken at room temperature with normal emission angle are plotted as a function of increasing Co coverages on the surface of the $\mathrm{Cr}_{2} \mathrm{O}_{3} / \mathrm{CrO}_{2}$ samples. The Co coverage is indicated in ML.

gen transport to the interface, or reduction of the $\mathrm{Cr}_{2} \mathrm{O}_{3}$ to a suboxide. There is little evidence to support the latter redox reaction, but it can not be wholly excluded by the data presented here.

Although $\mathrm{Pb}$ and $\mathrm{Co}$ at the interfaces of $\mathrm{Pb} / \mathrm{Cr}_{2} \mathrm{O}_{3} / \mathrm{CrO}_{2}$ and $\mathrm{Co} / \mathrm{Cr}_{2} \mathrm{O}_{3} / \mathrm{CrO}_{2}$ junctions are oxidized, the surface of $\mathrm{Pb}$ or $\mathrm{Co}$ top layer is metallic if $\mathrm{Pb}$ or $\mathrm{Co}$ film deposition is sufficiently thick. The evolution of the valence-band ultraviolet photoelectron spectra, with different Co coverages on $\mathrm{Cr}_{2} \mathrm{O}_{3} / \mathrm{CrO}_{2}$, is shown in Fig. 3. For a clean $\mathrm{Cr}_{2} \mathrm{O}_{3} / \mathrm{CrO}_{2}$ surface (zero monolayers Co coverage), the spectrum is the typical $\mathrm{Cr}_{2} \mathrm{O}_{3} / \mathrm{CrO}_{2}$ valence-band spectrum. ${ }^{5,18}$ With increasing Co coverage, the bands at 4 to $8 \mathrm{eV}$ from $\mathrm{Cr}-\mathrm{O} 2 p$ hybridization bands, and the band at $2 \mathrm{eV}$ binding energy dominated by the $\mathrm{Cr} 3 d$ orbitals, are suppressed while a strong feature at about $1 \mathrm{eV}$ becomes very prominent and the density of states at Fermi energy is increasingly well established. At Co coverages above $15 \mathrm{ML}$, the overlapping Co $3 d$ bands around $1 \mathrm{eV}$ binding energy are dominant and show the sharp Fermi edge characteristic of a metal. These photoemission spectra of the thick cobalt films on $\mathrm{Cr}_{2} \mathrm{O}_{3} / \mathrm{CrO}_{2}$ surface are characteristic of clean Co where the occupied $3 d$ bands dominate the region near the Fermi level in photoemission as both predicted ${ }^{27}$ and commonly observed in other photoemission experiments. ${ }^{28,29}$

In summary, we have used both ARXPS and ultraviolet photoemission to study the metal to chromium oxide interface. Both $\mathrm{Pb}$ and $\mathrm{Co}$ oxidize at the interface, and in the context of previous work investigating the $\mathrm{Co} / \mathrm{NiO}$ interface, it must be now recognized that many metal to metal-oxide interfaces involve further oxidation and reduction making such interfaces very heterogeneous. The interpretation of junction magnetoresistance results must now assume that ferromagnetic metals will NOT generally form abrupt interfaces with transition metal oxide dielectric barriers.

The support of the NSF (DMR 98-02126), the NSF Career program (Grant No. DMR 98-74657), the Office of Naval Research, and the Nebraska Research Initiative are gratefully acknowledged.

${ }^{1}$ J. S. Moodera, L. R. Kinder, T. M. Wong, and R. Meservey, Phys. Rev. Lett. 74, 3273 (1996).

${ }^{2}$ T. Miyazaki and N. Tezuda, J. Magn. Magn. Mater. 139, L231 (1995).

${ }^{3}$ J. M. de Teresa, A. Barthelemy, A. Fert, J. P. Contour, F. Montaigne, and P. Seneor, Science 286, 507 (1999).

${ }^{4}$ J. S. Parker, S. M. Watts, P. G. Inanov, and P. Xiong, Phys. Rev. Lett. 88, 196601 (2002).

${ }^{5}$ A. Sokolov, C.-S. Yang, L. Yuan, S.-H. Liou, R. Cheng, H.-K. Jeong, T. Komesu, B. Xu, C. N. Borca, P. A. Dowben, and B. Doudin, Europhys. Lett. 58, 448 (2002)

${ }^{6}$ A. M. Bratkovsky, Phys. Rev. B 56, 2344 (1997).

${ }^{7}$ J. D. M. Coey, A. E. Berkowitz, L. Balcells, F. F. Putris, and A. Barry, Phys. Rev. Lett. 80, 3815 (1998).

${ }^{8}$ H. Ohldag, A. Scholl, F. Nolting, S. Anders, F. U. Hillebrecht, and J. Stohr, Phys. Rev. Lett. 86, 2878 (2001).

${ }^{9}$ H. Ohldag, T. J. Regan, J. Stohr, A. Scholl, F. Nolting, J. Luning, C. Stamm, S. Anders, and R. L. White, Phys. Rev. Lett. 87, 247201 (2001).

${ }^{10}$ T. J. Regan, H. Ohldag, C. Stamm, F. Nolting, J. Luning, J. Stohr, and R. L. White, Phys. Rev. B 64, 214422 (2001).

${ }^{11}$ D. M. Lind, S. D. Berry, G. Chern, H. Mathias, and L. R. Testardi, Phys. Rev. B 45, 1838 (1992).

${ }^{12}$ D. M. Lind, S. D. Berry, G. Chern, H. Mathias, and L. R. Testardi, J. Appl. Phys. 70, 6218 (1991).

${ }^{13}$ J. A. Borchers, R. W. Erwin, S. D. Berry, D. M. Lind, E. Lochner and K. A. Shaw, Appl. Phys. Lett. 64, 38 (1994).

${ }^{14}$ M. J. Carey, A. E. Berkowitz, J. A. Borchers, and R. W. Erwin, Phys. Rev. B 47, 9952 (1993).

${ }^{15}$ J. A. Borchers, M. J. Carey, A. E. Berkowitz, R. W. Erwin, and C. F. Majkrzak, J. Appl. Phys. 73, 6898 (1993).

${ }^{16}$ M. Takano, T. Terashima, Y. Bando, and H. Ikeda, Appl. Phys. Lett. 51, 205 (1987).

${ }^{17}$ J. M. Rowell and L. Y. L. Shen, Phys. Rev. Lett. 17, 15 (1966).

${ }^{18}$ R. Cheng, B. Xu, C. N. Borca, A. Sokolov, C.-S. Yang, L. Yuan, S.-H. Liou, B. Doudin, and P. A. Dowben, Appl. Phys. Lett. 79, 3122 (2001).

${ }^{19}$ G. L. Rochlin and P. K. Hansma, Phys. Rev. B 2, 1460 (1970).

${ }^{20}$ N. Pilet, C. Borca, A. Sokolov, E. Ovtchenkov, B. Xu, and B. Doudin (unpublished).

${ }^{21}$ C. Battistoni, J. L. Dormann, D. Fiorani, E. Paparazzo, and S. Viticoli, Solid State Commun. 39, 581 (1981).

${ }^{22}$ I. Ikemoto, K. Ishii, S. Kinoshita, H. Kuroda, M. A. A. Franco, and J. Thomas, J. Solid State Chem. 17, 425 (1976).

${ }^{23}$ W. E. Morgan and J. R. Van Wazer, J. Phys. Chem. 77, 96 (1973).

${ }^{24}$ R. B. Shalvoy, G. B. Fisher, and P. J. Stiles, Phys. Rev. B 15, 1680 (1977).

${ }^{25}$ A. Lebugle, U. Axelsson, R. Nyholm, and N. Martensson, Phys. Scr. 23, 825 (1981).

${ }^{26}$ K. S. Kim, Phys. Rev. B 11, 2177 (1975).

${ }^{27}$ R. H. Victora and L. M. Falicov, Phys. Rev. B 28, 5232 (1983).

${ }^{28}$ R. Miranda, F. Yndurain, D. Chandesris, J. Lecant, and Y. Petroff, Phys. Rev. B 25, 527 (1982).

${ }^{29}$ R. Miranda, F. Yndurain, D. Chandesris, J. Lecant, and Y. Petroff, Surf. Sci. 117, 319 (1982). 